Edward A. Pascoe MD, Robert J. Hudson MD, Brian A. Anderson MD, Diamond A. Kassum MB, Ailsa Shanks RN, Morley Rosenbloom BSc (Hon), Ian R. Thomson MD

\section{High-dose thiopentone for open-chamber cardiac surgery: a retrospective review}

0.014 ), as was the duration of stay in intensive care (66 \pm 56 v.s $51 \pm 29 h, P=0.010$ ). Thiopentone did not increase the need for inotropic or mechanical support after bypass. In-hospital mortality was lower in Group $T$ than in Group $O(1.2 \%$ vs $9.5 \%, P=0.034$ ).

Conclusions: High-dose thiopentone delays extubation after open-chamber procedures. However, the rechnique appears safe, and further prospective investigation is justifiable.

Objectif: On a rapporté que les doses élevés de thiopentone diminuaient l'incidence de la dysfonction neurologique après la chirurgie à coeur ouvert. Cependant, cette méthode retarde l'extubation de la trachée et augmente le besoin de soutien inotrope après la circulation extracorporelle. Comme mesure d'assurance-qualité effectuée pour déterminer la sécurité du thiopentone à haute dose, nous avons révisé les dossiers de tous les patients de notre institution opérés pour une chirurgie à coeur ouvert entre le premier mars 1987 et le 31 décembre 1989.

Méthodes: Les dossiers de 236 patients ont été révisés rétrospectivement et 227 ont rencontré nos critères d'admissibilité. Les caractéristiques périopératoires des patients anesthésiés au thiopentone (groupe $T, n=80$ ) ont été comparées à celles des patients anesthésiés aux morphiniques (groupe $O, n=$ 147).

Résultats: La technique anesthésique était choisie par l'anesthésiste responsable. Dans le groupe $T$, le thiopentone $38.1 \pm 11.8 \mathrm{mg} \cdot \mathrm{kg}^{-1}$ érait perfusé de façon à produire un burst suppression électroencéphalographique pendant la circulation extracorporelle (CEC). Aucun accident cérébrovasculaire $n$ 'est survenu dans le groupe $T$ mais il y en a eu quatre dans le groupe $O$. L'intubation a été prolongée dans le groupe $T$ comparativement au groupe $O\left(39 \pm 51\right.$ vs $27 \pm 24 h_{1} P=$ $0,014)$ de même que la durée du séjour à l'unité des soins intensifs. Le thiopentone n'a pas augmenté le besoin de support inotrope ou mécanique après la CEC. La mortalité intrahospitalière était plus basse dans le groupe $T$ que dans le groupe $O(1,2 \%$ vs $9,5 \%, P=0,034)$.

Conclusions: Les doses élevées de thiopentone retardent l'extubation après les interventions à coeur ouvert. Cependant, la technique semble sùre, ce qui justifie des recherches ultérieures. 
Thiopentone has been used for the prevention of postoperative neurological dysfunction in patients undergoing cardiac surgical procedures involving cardiopulmonary bypass. Nussmeier and Slogoff found that thiopentone $39.5 \pm 8.4 \mathrm{mg} \cdot \mathrm{kg}^{-1}$ reduced the incidence of persistent neuropsychiatric complications in patients undergoing open-chamber procedures.' In that study, thiopentone infusion was begun before aortic cannulation, and continued until after separation from cardiopulmonary bypass. The dose of thiopentone was sufficient to produce episodes of electroencephalographic (EEG) burstsuppression lasting greater than $60 \mathrm{sec}$. Zaidan et al. subsequently found that thiopentone $33.1 \pm 11.1$ $\mathrm{mg} \cdot \mathrm{kg}^{-1}$ given in a similar manner did not prevent stroke in patients undergoing coronary artery bypass grafting. ${ }^{2}$ High-dose thiopentone has important sideeffects. Nussmeier and Slogoff, as well as Zaidan $e t$ al. found that high-dose thiopentone increased the need for inotropic support after cardiopulmonary bypass and delayed tracheal extubation, compared with more conventional anaesthetic techniques.

In March 1987 we began using high-dose thiopentone anaesthesia to prevent neurological complications during open-chamber procedures. Because of concern regarding the potentially deleterious effects of this therapy, we reviewed our experience. The review was begun in 1990 and completed in 1991.

\section{Methods}

We reviewed the records of all patients who underwent open-chamber surgery at our institution during a $34 \mathrm{mo}$ period from 1st March, 1987 to 31st December, 1989. We excluded patients who had emergency surgery, those who went to the operating room directly from an intensive care unit (ICU), those who underwent deep hypothermia and circulatory arrest, and those who died as a consequence of technical misadventure.

Anaesthetic management was at the discretion of the attending anaesthetist. High-dose thiopentone was administered as described by Nussmeier and Slogoff. Patients given thiopentone underwent continuous monitoring of the unprocessed electroencephalogram (EEG) (Lifescan@, Neurometrics, Inc.). Immediately before aortic cannulation, $\cdot$ a thiopentone infusion was begun and continued until after separation from cardiopulmonary bypass. The infusion was titrated to achieve EEG burst-suppression, with isoelectric periods lasting approximately one minute. Moderately hypothermic cardiopulmonary bypass $\left(25-28^{\circ} \mathrm{C}\right)$ with $\alpha$-stat $\mathrm{pH}$ management, and intermittent, antegrade, cold sanguineous cardioplegia were almost universally employed. Arterial inflow filters were always used. Choice of oxygenator and the use of pulsatile perfusion were not con- trolled. Most thiopentone was infused during cooling and rewarming, as requirements were minimal once the target nasopharyngeal temperature was achieved. $\mathrm{Pa}$ tients who were not given high-dose thiopentone were anaesthetized with a high-dose opioid technique. Before undertaking our review we decided to assign patients to the high-dose thiopentone group if they received $>15$ $\mathrm{mg} \cdot \mathrm{kg}^{-1}$ thiopentone during the procedure. This was because Slogoff et al. previously demonstrated that thiopentone $15 \mathrm{mg} \cdot \mathrm{kg}^{-1}$ was not effective in reducing the incidence of neuropsychological dysfunction after cardiac surgery. ${ }^{3}$ All records were reviewed by a nurseclinician with several years experience in perioperative management of cardiac surgical patients. She extracted all pertinent details from the chart, including information about anaesthesia, surgery, and neurological status. A neurologist, who was unaware of anaesthetic management, reviewed all cases of possible neurological injury and determined whether or not a stroke had occurred. Stroke was defined as a new focal neurological deficit apparent upon awakening from anaesthesia. Perioperative death was defined as in-hospital death on the same admission.

Continuous variables are expressed as mean \pm standard deviation. Statistical comparisons between anaesthetic groups were performed using Student's $t$ test, and $\chi^{2}$ analysis. A $P$ value of $\leq 0.05$ was considered indicative of statistical significance.

\section{Results}

Two hundred and thirty-six patients underwent openchamber surgery during the period of the review. Nine patients were excluded from analysis. Eight of these underwent emergency procedures or were transferred to the operating room from an ICU, and one underwent deep hypothermic arrest. Of the excluded patients, four received high-dose thiopentone and five high-dose opioid anaesthesia. One excluded patient, who received opioid anaesthesia, died. No deaths were deemed secondary to technical misadventure.

Two hundred and twenty-seven patients met our inclusion criteria. Eighty received high-dose thiopentone (Group T) and 147 were given high-dose opioid anaesthesia (Group $\mathrm{O}$ ). The thiopentone dose in Group $\mathrm{T}$ was $38.1 \pm 11.8 \mathrm{mg} \cdot \mathrm{kg}^{-1}$. Seventeen of 147 patients in Group $O$ received thiopentone $5.7 \pm 3.5 \mathrm{mg} \cdot \mathrm{kg}^{-1}$, primarily at induction. Seven anaesthetists participated, and they differed in their use of high-dose thiopentone. Three anaesthetists administered $85 \%$ of the anaesthetics in Group T, and four others gave $83 \%$ of the anaesthetics in Group O. Seven surgeons participated. The distribution of cases by surgeon did not differ between groups. The patient characteristics are summarized in 
TABLE I Demographics

\begin{tabular}{lcc}
\hline & $\begin{array}{c}\text { Group } T \\
(n=80)\end{array}$ & $\begin{array}{c}\text { Group } O \\
(n=147)\end{array}$ \\
\hline Agc (yr) & $60 \pm 16$ & $61 \pm 14$ \\
Sex (M:F) & $37: 43$ & $81: 66$ \\
Cardiac index $\left(\mathrm{L} \cdot \mathrm{min}^{-1} \cdot \mathrm{m}^{-2}\right)+$ & $2.53 \pm 0.76$ & $2.52 \pm 0.77$ \\
ASA physical status & & \\
- II & $8(10)$ & $8(5.4)$ \\
- III & $28(35)$ & $53(36.1)$ \\
- IV & $44(55)$ & $86(58.5)$ \\
Operation performed & & \\
- ASD & $7(8.8)$ & $8(5.4)$ \\
- AVR & $28(35.0)$ & $45(30.6)$ \\
- AVR,+ & $13(16.3)$ & $29(19.7)$ \\
- MVR & $18(22.5)$ & $29(19.7)$ \\
- MVR,+ & $3(3.8)$ & $16(10.9)$ \\
- AVR.MVR & $9(11.3)$ & $14(9.5)$ \\
- AVR,MVR,+ & $1(1.3)$ & $4(2.7)$ \\
Other & $1(1.3)$ & $2(1.4)$ \\
Reoperation & $7(8.8)$ & $19(12.9)$ \\
\hline
\end{tabular}

tFigures in parentheses are percentages.

FImmediately before induction, Group T $(n=73)$, Group $O(n=135)$.

AVR $=$ aortic valve replacement; $M V R=$ mitral valve repair or

replacement; $A S D=$ atrial scptal defect repair; Other $=$ other open

cardiac procedures.

+ Additional cardiac procedure(s) (e.g., coronary artery bypass graft-

ing, aortic root replacement).

Table I. The two groups did not differ with respect to age, sex, American Society of Anesthesiologists (ASA) physical status, type of procedure, or the incidence of reoperation. The cardiac index determined immediately before induction of anaesthesia did not differ between groups. Preoperative left ventricular ejection fraction was not recorded, because this information was not uniformly available and could be misleading in patients with valvular heart disease (e.g., mitral regurgitation). Cardiopulmonary bypass was conducted similarly in both groups (Table II). There were no intergroup differences in the duration of bypass, or the duration of aortic cross-clamping. The lowest nasopharyngeal temperature during bypass was slightly greater in Group $\mathrm{T}$ than in Group $\mathrm{O}\left(26 \pm 3^{\circ} \mathrm{C}\right.$ vs $\left.25 \pm 3^{\circ} \mathrm{C}, P=0.024\right)$.

Morbidity and mortality are summarized in Table III. There were no differences between groups with respect to the use of inotropic support or intraaortic balloon counterpulsation after cardiopulmonary bypass. However, both the time to extubation and the duration of intensive care unit (ICU) stay were prolonged in Group T $(P=0.014$ and $P=0.010$, respectively). Within Group T, there was no relationship between the dose of thiopentone used and the duration of mechanical ventilation $\left(r^{2}=0.004\right)$. There was no intergroup difference in the duration of hospitalization.

Overall mortality was $6.6 \%$. Most deaths were either
TABLE II Management of Cardiopulmonary Bypass

\begin{tabular}{lcl}
\hline & $\begin{array}{c}\text { Group } T \\
(n=80)\end{array}$ & $\begin{array}{l}\text { Group } O \\
(n=147)\end{array}$ \\
\hline $\begin{array}{l}\text { Duration of CPB (min) } \\
\text { Duration of X-clamp (min) }\end{array}$ & $151 \pm 64$ & $164 \pm 67$ \\
$\begin{array}{l}\text { Lowest nasopharyngeal } \\
\text { Icmperature }\left({ }^{\circ} \mathrm{C}\right)\end{array}$ & $95 \pm 46$ & $101 \pm 41$ \\
Arterial line filter & $26 \pm 3$ & $25 \pm 3^{*}$ \\
Oxygenator bubble: Membrane & 80 & 147 \\
Pulsatile: Nonpulsatile & $27: 53$ & $45: 102$ \\
\hline
\end{tabular}

$* P<0.05$ between groups.

TABLE III Morbidity and mortality $\dagger$

\begin{tabular}{lcc}
\hline & $\begin{array}{c}\text { Group } T \\
(n=80)\end{array}$ & $\begin{array}{c}\text { Group O } \\
(n=147)\end{array}$ \\
\hline Inotropic support & $44(55.0)$ & $68(46.3)$ \\
Intraaontic balloon counterpulsation & $4(5.0)$ & $18(12.2)$ \\
Time to extubation (hr) $\ddagger$ & $39 \pm 51$ & $27 \pm 24^{*}$ \\
Time in intensive carc (hr) $\ddagger$ & $66 \pm 56$ & $51 \pm 29^{*}$ \\
Hospital stay (days) $\neq$ & $19 \pm 13$ & $21 \pm 20$ \\
Stroke $\$$ & $0(0.0)$ & $4(2.8)$ \\
Death & $1(1.2)$ & $14(9.5)^{*}$ \\
\hline
\end{tabular}

$* P<0.05$ between groups.

†Figure in parcntheses are percentages.

$\ddagger$ Measured from arrival in intensive care.

$\$$ Excludes 5 intraoperative deaths in Group 0 .

TABLE IV Predictors of Death

\begin{tabular}{llll}
\hline & $\begin{array}{l}\text { Nonsurvivors } \\
(n=/ 5)\end{array}$ & $\begin{array}{l}\text { Survivors } \\
(n=212)\end{array}$ & $P$-value \\
\hline $\begin{array}{l}\text { Reoperation } \\
\begin{array}{l}\text { Aortic clamp time (min) } \\
\text { Cardiopulmonary bypass } \\
\quad \text { time (min) }\end{array}\end{array}$ & $121 \pm 55$ & $\begin{array}{l}19 \\
97 \pm 41\end{array}$ & $\begin{array}{l}0.0001 \\
0.033\end{array}$ \\
$\begin{array}{l}\text { Anaesthetic } \\
\text { - Thiopentone }\end{array}$ & $233 \pm 98$ & $154 \pm 60$ & 0.0001 \\
- Opioid & 1 & 79 & 0.034 \\
\hline
\end{tabular}

cardiac in origin or secondary to multiorgan failure initiated by circulatory insufficiency. Mortality was lower in Group T than in Group $O(1.2 \%$ vs $9.5 \%$ respectively, $P$ $=0.034$ ). There were five intraoperative deaths, all in Group 0 . These patients were excluded from our analysis of the incidence of stroke. The overall stroke rate was $1.8 \%$, and did not differ between groups. All four patients with strokes were in Group 0 . Each had new onset left hemiparesis, apparent upon awakening five to seven hours postoperatively.

In addition to anaesthetic technique, several other potential predictors of death were identified (Table IV). These were: reoperation, the duration of aortic crossclamping, and the duration of cardiopulmonary bypass. Variables which did not predict death included sex, car- 
TABLE V Mortality of various surgical procedures

\begin{tabular}{llll}
\hline Procedure & Nonsurvivors & Survivors & $\%$ \\
\hline ASD & 0 & 15 & 0 \\
AVR & 2 & 71 & 2.7 \\
AVR+ & 3 & 39 & 7.1 \\
MVR & 4 & 43 & 8.5 \\
MVR+ & 2 & 17 & 10.5 \\
AVR MVR & 3 & 20 & 13.0 \\
AVR MVR+ & 1 & 4 & 20.0 \\
Other & 0 & 3 & 0 \\
\hline
\end{tabular}

AVR = aortic valve replacement; $M V R=$ mitral valve repair or replacement; ASD = atrial septal defect repair; Other = other open cardiac procedures.

+ Additional cardiac procedure(s) (e.g., coronary artery bypass grafting, aortic root replacement).

diac index, surgeon, type of oxygenator, and the use of pulsatile flow. Simple procedures were associated with the lowest, and complex procedures with the highest mortality (Table V). However, there were no statistically significant differences in mortality among the various procedures.

\section{Discussion}

Our primary motivation in conducting this review was to examine the safety of high-dose thiopentone. Our results are reassuring. Available data, including ours, indicate that high-dose thiopentone does not increase mortality. Collectively, in our study and that of Zaidan et al., 229 adult patients received high-dose thiopentone with only two deaths $(0.9 \%, 95 \%$ confidence interval $0.1-3.1 \%$ ). Our results also suggest that high-dose thiopentone can be safely used in patients undergoing high-risk, open-chamber procedures. Twenty-six patients in Group $\mathrm{T}$ underwent combined procedures or double valve replacement with no deaths (95\% confidence interval $0-11 \%$ ).

The frequency with which inotropic agents or intraaortic balloon counterpulsation were employed after cardiopulmonary bypass was not increased in Group T. Thus, we found no evidence of irreversible myocardial depression caused by high-dose thiopentone. However, both Nussmeier and Slogoff, and Zaidan et $a l$., noted an increased requirement for inotropic support after cardiopulmonary bypass in open-chamber surgery, and coronary artery bypass grafting, respectively. ${ }^{1,2}$ No explanation for our different result is apparent.

Thiopentone delayed tracheal extubation by an average of $12 \mathrm{hr}$. Similar findings were reported by Nussmeier and Slogoff, and by Zaidan et al. ${ }^{1.2}$ In those studies high-dose thiopentone was associated with an average delay of five hours in time to extubation. Clearly, delayed extubation is a consistent and clinically important adverse effect of high-dose thiopentone. We found no correlation between thiopentone dose and time to extubation. However, thiopentone was titrated to obtain the same pharmacological endpoint, EEG burstsuppression, in all patients. Using this endpoint probably compensates for interpatient pharmacokinetic and/or pharmacodynamic variability, producing similar recovery times for most patients. Patients who required large doses of thiopentone may have been those who cleared the drug rapidly, and/or were insensitive to its effects. Thus, they would not be expected to experience delayed recovery relative to other patients who received thiopentone.

High-dose thiopentone did not reduce the incidence of stroke. New neurological deficits upon recovery from anaesthesia were noted in $0 \%$ and $2.8 \%$ of the thiopentone and opioid anaesthesia groups respectively. The true incidence of stroke was almost certainly underestimated because of the retrospective nature of our study. Nussmeier and Slogoff noted focal neurologic deficits in $1.1 \%$ of their thiopentone group compared with $6.5 \%$ of their placebo group $(P=0.07)$ on the first postoperative day.' Neither study has adequate statistical power to permit conclusions regarding the efficacy of high-dose thiopentone for prevention of stroke apparent soon after open-chamber surgery. Larger trials would be needed to definitively address this issue. Available data suggest that thiopentone does not reduce the incidence of stroke occurring during coronary artery bypass grafting. ${ }^{2}$

The use of high-dose thiopentone was associated with a lower mortality (1.2\% vs $9.5 \%)$ than opioid anaesthesia. Selection bias may explain this result. However, Groups $T$ and $O$ did not differ with respect to demographics, type of surgery, management of cardiopulmonary bypass, duration of bypass, or duration of aortic cross-clamping. Many patients in Group T were elderly and underwent complex surgical procedures with prolonged aortic cross-clamp times. In patients undergoing coronary artery surgery, Zaidan et al. noted a $0.7 \%$ mortality with high-dose thiopentone and a $2.6 \%$ mortality in controls $(P=0.18)^{2}$ Although the possibility that thiopentone favourably alters mortality cannot be ruled out, such a conclusion should not be drawn from this retrospective, uncontrolled study. Subtle differences in the complexity of procedures could explain our results. Some high-risk procedures, such as reoperation and mitral valve replacement combined with another cardiac operation, tended to be more frequent in Group $O$, although none of these differences were statistically significant. It is also possible that the lower mortality in Group $\mathrm{T}$ was related to the anaesthetist rather than to the anaesthetic. Patients managed by any of the three anaesthetists who consistently employed high-dose thiopen- 
tone anaesthesia had a low mortality $(1 / 94,1.1 \%)$ compared with those managed by either of the other four anaesthetists $(14 / 133,10.5 \%, P=0.01)$. The type of anaesthetic and the anaesthetist are so strongly correlated that it is impossible to determine confidently the relative impact of either variable on outcome. Slogoff $e t$ al. reported that the anaesthetist was a predictor of perioperative myocardial infarction in patients undergoing coronary artery bypass grafting. ${ }^{4}$ Such an effect may account for our observations.

Patient management in our study differed in several ways compared with that described by Nussmeier and Slogoff. We used moderate hypothermia and arterial line filtration routinely, whereas they used normothermia (nasopharyngeal temperature $>34^{\circ} \mathrm{C}$ ) without arterial line filtration. The duration of cardiopulmonary bypass in our study was approximately three times longer. Despite this, our thiopentone dose was similar to theirs $(38.1 \pm 11.8$ vs $39.5 \pm 8.4$ respectively). This probably reflects the fact that we administered little or no thiopentone during hypothermia. Thus, when moderate hypothermia is employed, complicated procedures and prolonged bypass times need not result in inordinately large doses of thiopentone. High-dose thiopentone anaesthesia appears to be safc in patients undergoing open-chamber cardiac surgery. Mortality, requirements for inotropic therapy, and the use of intraaortic balloon counterpulsation were not increased in patients given high-dose thiopentone. However, highdose thiopentone delays extubation and prolongs postoperative stay in ICU. These side-effects have important resource implications that will discourage its use. Definitive investigation of the risk-benefit ratio for high-dose thiopentone anaesthesia is justifiable, but will require a prospective, controlled, multicentre approach.

\section{References}

1 Nusssmeier NA, Arlund C, Slogoff S. Neuropsychiatric complications after cardiopulmonary bypass: cerebral protection by a barbiturate. Anesthesiology 1986; 64: 165-70.

2 Zaidan JR, Klochany A, Martin WM, Ziegler JS, Harless

$D M$, Andrews $R B$. Effect of thiopental on neurologic outcome following coronary artery bypass grafting.

Anesthesiology 1991; 74: 406-11.

3 Slogoff S, Girgis KZ, Keats AS. Etiologic factors in neuropsychiatric complications associated with cardiopulmonary bypass. Anesth Analg 1982; 61: 903-11.

4 Slogoff $S$, Keats AS. Does perioperative myocardial ischemia lead to postoperative myocardial infarction? Anesthesiology 1985; 62: 107-14. 